\title{
OS DIREITOS REPRODUTIVOS NA ERA DA BIOTECNOLOGIA: REFLEXÕES ÉTICO-JURÍDICAS ACERCA DA LIBERDADE DE PROCRIAÇÃO FRENTE À DIGNIDADE DA PESSOA HUMANA
}

\section{ETHICAL AND LEGAL REFLECTIONS ON FREEDOM OF PROCREATION AGAINST HUMAN DIGNITY}

\author{
Maria Rosineide da Silva Costa ${ }^{1}$ \\ Mariana Faria Filard ${ }^{2}$
}

\section{RESUMO}

O presente trabalho analisa a problemática acerca do embrião humano como sujeito de direitos e dotado de dignidade frente à liberdade de procriação assistida. Inúmeros são os questionamentos que circundam os desafios decorrentes dos novos direitos na área da biotecnologia e os debates éticos e morais que envolvem a manipulação de embriões nessas tecnologias quanto ao respeito à dignidade destes seres. A dignidade da pessoa humana é um valor de grande magnitude, que deve servir como sustentáculo axiológico em progressos que envolvam o ser humano e a humanidade como um todo.

Palavras-chave: Biotecnologia; Reprodução assistida; Procriação; Dignidade da pessoa humana; Embrião.

\begin{abstract}
The present work analyzes the problematic of the human embryo as a subject of rights and endowed with dignity in the face of the freedom of assisted procreation. There are many questions that surround the challenges arising from the new rights in the area of biotechnology and the ethical and moral debates that involve the manipulation of embryos in these technologies regarding the respect for the dignity of these beings. The dignity of the human person is value of great magnitude, which should serve as an axiological mainstay in progress that involves the human being and humanity as a whole.
\end{abstract}

Keywords: Biotechnology; Assisted reproduction; Procreation Dignity of human person; Embryo.

\footnotetext{
${ }^{1}$ Mestre em Direito do Programa de Pós-Graduação Strictu Sensu da Universidade do Vale do Itajaí- UNIVALI, Santa Catarina, (Brasil). Advogada. Professora do Curso de Graduação em Direito do Centro Universitário do Norte- UNINORTE, Manaus, Amazonas. E-mail: neide.giga @ yahoo.com.br

${ }^{2}$ Mestre em Direito do Programa de Pós-Graduação Strictu Sensu da Universidade do Vale do Itajaí- UNIVALI, Santa Catarina, (Brasil). Advogada.
} 


\section{INTRODUÇÃO}

O século XX, irrefragavelmente foi palco das maiores descobertas e extraordinárias conquistas científicas em diversas áreas do conhecimento, notadamente no campo da biotecnologia, cujos surpreendentes avanços possibilitaram à humanidade vivenciar e experimentar benefícios dantes jamais cogitados.

Revolucionários progressos foram alcançados na área das ciências biomédicas das quais, merecem destaque aqueles referentes às novas técnicas no campo da medicina reprodutiva que sem dúvida, representaram um incontestável avanço no campo da procriação humana, na medida em que as descobertas nessa área trouxeram soluções para o problema de infertilidade possibilitando a realização do sonho de procriação para aqueles que não o alcançaram de forma espontânea.

No entanto, por entrar numa seara que envolve utilização de técnicas de manipulação de organismos vivos despertam também muitas preocupações com relação ao grande poder dessas tecnologias para modificar a realidade existente e os limites éticos aceitáveis no âmbito dessas mudanças científicas quanto aos caminhos que podem ser trilhados, considerando a necessidade de harmonização entre ciência e direito e ainda, os seus reflexos sobre a humanidade e a preservação da dignidade da pessoa humana.

Dentre os dilemas que são suscitados em decorrência dos avanços biotecnológicos, se insere a questão relacionada ao estatuto jurídico do Embrião humano e a dignidade desses seres, cujo tema tem sido objeto de muitos trabalhos científicos e amplas discussões filosóficas dada a sua complexidade, assim como pelas indefinições sobre a possibilidade de serem estes seres, dotados de dignidade de modo a terem seus direitos fundamentais resguardados em função dessa condição.

Considerando essas nuances, o presente trabalho cifra-se em analisar a problemática referente à dignidade do embrião humano, como sujeito de direitos frente à liberdade de procriação mediante utilização de técnicas reprodutivas artificiais, dando enfoque aos dilemas sociais decorrentes dos progressos das ciências biotecnológicas bem como, às tecnologias de reprodução artificial e a problemática decorrente da utilização de embriões na manipulação dessas tecnologias, discutindo as questões éticas decorrentes da utilização dessas técnicas e os 
debates relacionados ao embrião humano como sujeito de direitos e dotado de dignidade, atributo inerente a todo ser humano pela condição de ser humano.

\section{OS PROGRESSOS BIOTECNOLÓGICOS E OS DILEMAS SOCIAIS}

$\mathrm{O}$ século $\mathrm{XX}$, inegavelmente foi revolucionário em termos de novos conhecimentos tecnocientíficos promovendo espantosos avanços na área da biotecnologia com a utilização de novas tecnologias sobre o ser humano, causando diversos impactos tanto de ordem social, como política e econômica.

O termo biotecnologia comporta uma grande diversidade de definições. Nas palavras de Burillo (in CASABONA, 2002, p.227), trata-se de "um só termo com múltiplas possibilidades". A palavra biotecnologia é composta da fusão das palavras gregas "bios" que significa vida com a palavra "tecnologia" que significa estudo das ferramentas (SANTOS, 2004).

$\mathrm{O}$ artigo $2^{\mathrm{o}}$ da Convenção da Biodiversidade biológica define biotecnologia como "qualquer aplicação tecnológica que utilize sistemas biológicos, organismos vivos ou seus derivados, para fabricar ou modificar produtos ou processos".

Para Santiago Grisólia (in CASABONA, 2002, p.16) biotecnologia é "o desenvolvimento e uso de tecnologias baseadas no conhecimento de matéria viva para obter melhores produtos para uso humano".

Acrescenta o autor que as extraordinárias e inéditas utilizações da biotecnologia decorrem de investigações e estudos interdisciplinares em diversas áreas, dentre as quais, a medicina, farmacêutica e biotecnológica do meio ambiente (GRISÓLIA in CASABONA, 2002 p. 17).

No período que correspondente ao final do século XIX, com a evolução do conhecimento científico, sobre os "micróbios", e da descoberta da célula, houve uma expansão na utilização de organismos vivos para a produção de produtos com finalidades preventivas e terapêuticas, surgindo então as vacinas, os antibióticos, e diversas matérias primas para a indústria alimentícia e milhares de outros produtos que hoje integram o cotidiano do homem (GRISÓLIA, in CASABONA, 2002, p. 16). 
Vista pela sociedade como um relevante instrumento, dotado de capacidade de promover significativas melhorias na qualidade de vida da sociedade, a biotecnologia também é considerada potencialmente perigosa para os seres humanos e o meio ambiente haja vista o risco da prática de abusos.

Observa Burillo (in Casabona, 2002, p. 249), que quando algo novo e espantoso está acontecendo na área da biotecnologia liberando "forças tão poderosas," é motivo de preocupação para toda a humanidade, a qual vê com certo receio toda essa transformação, que na verdade, se utilizada de forma adequada poderá trazer grandes benefícios nas diversas áreas do conhecimento, como a medicina, engenharia, agricultura etc.

Segundo o autor, o medo demonstrado pela sociedade é fruto da ignorância, que também acaba sendo a responsável pelo uso inadequado e restrições ao imenso bem que se pode produzir com a produção de tecnologias.

Um exemplo do afirmado pode ser percebido com relação aos alimentos transgênicos, evidenciando-se, esse receio e antagonismo, em determinados segmentos da sociedade, como os ambientalistas e a comunidade jurídica.

Conforme ressalta Rodrigues (2002, p. 118), constata-se, com relação aos alimentos transgênicos, a existência de vários questionamentos surgidos acerca da segurança da utilização dessas técnicas de experimentação e das consequências para o meio ambiente e saúde, uma vez que não se sabe com certeza quais os riscos decorrentes da utilização dessa nova tecnologia.

O citado exemplo deixa evidente que mesmo a despeito da questão dos alimentos transgênicos nos últimos anos terem tomado uma nova direção, com a criação de mecanismos internacionais de biossegurança, ainda existe por parte da sociedade uma grande resistência, em aceitar com bons olhos as práticas transgênicas, por não haver pleno conhecimento das medidas preventivas tomadas por partes das autoridades em relação ao controle dos riscos e das consequências que delas poderão surgir no futuro da humanidade (RODRIGUES, 2002, p.118).

A era da biotecnologia, no dizer de Rifkin (1999, p. 3) promoveu imensuráveis transformações, não apenas no nosso cotidiano, afetando nossa consciência individual e coletiva, como também no futuro da nossa civilização e no nosso próprio ecossistema, trazendo riscos e benefícios assustadores de se contemplar. Assevera que "a humanidade 
nunca esteve tão despreparada para os novos desafios e riscos resultantes de tais avanços que se avizinham no horizonte".

O autor também ressalta, que desde há muitos anos tem expressado sua preocupação com as implicações e os impactos sociais, econômicos e éticos que os avanços na área da biotecnologia poderiam ocasionar. Na opinião do autor é importante refletir sobre

[...] qual será o impacto emocional e intelectual ao crescermos num mundo onde a vida é tratada como uma invenção?" Quais os riscos de se tentar desenhar um ser humano mais perfeito? Estas são algumas das preocupações de alguns críticos em relação à velocidade espantosa dos avanços biotecnológicos.

As transformações econômicas da história se operaram no momento em que determinadas forças sociais e tecnológicas se uniram, para criar o que ele denomina de "matriz operacional do século biotecnológico" integrada por diversos processos dentre os quais a capacidade para criar técnicas biotecnológicas, que permitem aos cientistas a exploração e recursos genéticos para fins econômicos, além de possibilitar uma industria global da ciência da vida, que segundo o autor, já começa a exercer um domínio de uma "força sem precedentes que atua sobre os vastos recursos biológicos do planeta (RIFKIN, 1999, p. 238).

Para o autor americano existem muitas formas de celebrar a ciência, porém os cientistas ao se dedicarem ao desenvolvimento de novas tecnologias para a criação de organismos eficientes e uteis à sociedade não devem se prender a uma visão "baconiana" de um mundo reducionista sem a devida acuidade quanto as consequências resultantes das tecnologias desenvolvidas ( RIFKIN, 1999, p. 238).

A utilização de novas biotecnologias sobre o ser humano, segundo Brauner (in Sarlet; Leite, 2008, p. 175), produzem significativas repercussões no meio social na medida em que envolvem interesses de cunho não apenas político como sociais e econômicos.

Os progressos alcançados nesse ramo do conhecimento, se refletem não apenas na esfera social como também no âmbito do direito e, conforme assinala o professor GARCIA (in Cruz; Stelzer, 2009, p.176) promovem uma modificação nos direitos fundamentais para, "incluir novas demandas da sociedade em transformação", haja vista o caráter dinâmico dos direitos fundamentais frente à necessidade de acompanhar a evolução social. 
Na opinião de Brauner (2008, p. 179-180), a era da biotecnologia, sem dúvida traduz uma realidade incontestável nos dias atuais gerando na sociedade grande expectativas com relação às inúmeras possibilidades terapêuticas que as técnicas desenvolvidas nessa área podem promover.

No entanto, embora sejam incontestes as promissoras possibilidades dos benefícios que essas tecnologias podem trazer conferindo, sem dúvidas, melhorias de vida a humanidade, existe também a preocupação com as questões éticas que envolvem as pesquisas e as práticas científicas desenvolvidas nessa área. Nesse sentido a autora assevera que

\begin{abstract}
As questões éticas envolvendo intervenções na saúde humana, novas terapias e pesquisas genéticas passaram a fazer parte da preocupação cotidiana dos indivíduos, que têm resultado em forte pressão para a elaboração de novas formulações jurídicas que desempenham o papel de ajustar o corpo normativo aos anseios da sociedade, que podem ser sintetizados no acesso a novas terapias e medicamentos (BRANER, in SARLET; LEITE, p. 176)
\end{abstract}

A constatação de que as imensuráveis descobertas no campo da biotecnologia tem representado grandes avanços no campo das ciências biomédicas, com a possibilidade de melhores condições de vida para a humanidade, tem conduzido a aceitação social das inovações surgidas na área da biotecnologia. Todavia, diante da rapidez com que tais avanços se propagam no mundo, a questão, segundo Brauner (2008, p. 178) deve ser tratada com observância a diversos aspectos, dentre os quais, a liberdade de pesquisa associada à segurança da integridade física e o bem estar geral dos indivíduos.

Afirma a autora que tabus e preconceitos não podem servir de obstáculos para os avanços e progressos científicos, pois se assim se sucedesse decerto haveria um comprometimento dos importantes interesses sociais a serem alcançados. No entanto, a aceitação de inovações que venham de algum modo intervir sobre o ser humano deve ser seguida por critérios que se revistam de parcimônia e responsabilidade.

Segue reforçando que o debate filosófico incorporado pelo discurso jurídico é fundamentado pela consagração do principio da dignidade da pessoa humana que, na definição de Sarlet significa "a qualidade intrínseca e distintiva de cada ser humano que o faz merecedor do mesmo respeito e consideração por parte do Estado e da comunidade". 


\section{A PROCRIAÇÃO ARTIFICIAL COMO UM DIREITO FUNDAMENTAL E SUAS REPERCUSSÕES ÉTICO-JURÍDICAS}

O ingresso no período histórico denominado "modernidade", permitiu ao mundo uma nova visão acerca das principais ideologias que se impuseram nesse período destacando-se as ideias que permitiram a defesa das liberdades individuais denominadas de direitos humanos (AGUILAR, 2002, P. 85).

Desde então, a busca rumo à afirmação dos direitos fundamentais, conforme salienta Gorczevski (2005, p. 73), tem representado uma marcha que, embora já tenha percorrido várias etapas de evolução, ainda continua em desenvolvimento, haja vista o caráter dinâmico de tais direitos e ainda, o fato de esses direitos representarem "frutos que se sedimentam na evolução e nas contradições da sociedade".

O processo de generalização dos direitos fundamentais, no pensar de Peces-Barba (1995, p. 155), pressupõe a conjunção dos direitos econômicos e sociais, direitos de prestação que não se afastam da tradição inicial senão que passam a integrá-lo, resultando esse processo, no surgimento de varias dimensões de direitos fundamentais sinalizando para uma intrínseca relação entre o ético, o político e o jurídico apontando para a necessidade de reflexões no campo da ética.

Desde que passaram a ser reconhecidos constitucionalmente, os direitos fundamentais experimentaram diversas mudanças, tanto no concernente ao seu conteúdo como na titularidade, eficácia e concretude. Nesse sentido é que se fala em existência de diversas gerações de direitos fundamentais que não se substituem, mas que somente se complementam (SARLET 2010, p. 45).

Dentre as diferentes dimensões de direitos fundamentais, surgem aqueles decorrentes da utilização de novas tecnologias assumindo significativa relevância em razão de sua intrínseca relação com a intimidade individual do ser humano, como é o caso das garantias contra manipulações genéticas, considerados pela doutrina como direitos de terceira dimensão (SARLET 2010, p. 50).

O processo de especificação dos direitos fundamentais possibilitou explicar uma serie de transformações decorrentes do fenômeno dos "novos" direitos fundamentais explicados por Bobbio (1992, p. 63) como integrantes de uma quarta linha evolutiva dos 
direitos fundamentais, a qual abrange dentre outros, os direitos especificados quanto ao conteúdo vinculados diretamente com a vida humana, aí incluído o direito à reprodução assistida.

Os direitos reprodutivos nas palavras de Piovesan; Pirotta (in Piovesan, 2010, p. 306) equivalem ao "conjunto dos direitos básicos relacionados ao livre exercício da sexualidade e da reprodução humana. Para os autores, esse conceito abrange um serviço de saúde capaz de garantir informação acerca da liberdade reprodutiva.

Ainda na opinião dos autores, os direitos reprodutivos na Constituição brasileira estão diretamente ligados aos princípios da cidadania e da dignidade da pessoa humana e com os objetivos fundamentais de promover o bem comum sem preconceitos de origem, raça, sexo, cor, idade e quaisquer outras formas de discriminação.

Ao fazer menção sobre a legitimidade da procriação assistida Robert Wider (2007 p. 63), explica que o direito a constituir família é um direito fundamental previsto em diversas ordens constitucionais e recepcionado em vários diplomas jurídicos na legislação pátria.

Apesar de assumirem um novo papel nas sociedades contemporâneas, o que em muitos casos ocasiona a postergação da maternidade, as mulheres continuam trazendo em si o desejo pela procriação, considerado por Costa (in Souza; Moura; Grynszpan, 2008 p. 109) como um desejo intimamente relacionado com a "identidade do gênero feminino".

A história da fertilidade humana, nas palavras de Queiroz (2001, p. 65), demonstra que a esterilidade sempre foi vista como um fator negativo, algumas vezes até mesmo considerada como uma maldição ou castigo divino. Na própria bíblia hebraica é possível constatar vários casos de mulheres que eram estigmatizadas ou se sentiam em opróbrio pelo fato de serem estéreis ${ }^{3}$.

Esse "estigma milenar" em relação à infertilidade feminina produz seus reflexos até os dias de hoje de modo que, a busca pela procriação se tornou quase uma obsessão e, em algumas culturas, a maternidade continua sendo fator que influencia na aceitação da mulher em determinados grupos sociais, de modo que as mulheres continuam a busca pela fertilidade

\footnotetext{
${ }^{3} \mathrm{E}$ a sua rival excessivamente a provocava, para a irritar; porque o Senhor lhe tinha cerrado a madre. (1 Samuel 1:6).

Quando Raquel viu que não dava filhos a Jacó, teve inveja de sua irmã. Por isso disse a Jacó: "Dê-me filhos ou morrerei!" (Gênesis 30:1)
} 
para se sentirem realizadas e para afirmação de sua identidade feminina. (QUEIROZ, 2001, p. $67)$.

No entanto, embora a sociedade atual já tenha mudado sua mentalidade em relação aos estigmas da infertilidade que dominavam o pensamento social na antiguidade, esta continua sendo um problema ainda presente que traz preocupação aos seres humanos. Fatores biológicos e outros externos como o estresse da vida moderna, má qualidade de vida abuso de substâncias químicas etc., são fatores que influenciam diretamente na possibilidade de procriação natural da espécie humana (Santos, 1993, p. 22-23).

O desejo irrefreável de procriação que sempre se fez presente na história da humanidade estimulou a ciência ao desenvolvimento de tecnologias para solucionar o problema de infertilidade, tendo essas técnicas empreendido incomensuráveis avanços no campo da reprodução humana (QUEIROZ, 2001, P. 68-969).

Nesse sentido, oportuno mencionar as palavras de Wider (2007, p. 63) segundo as quais "O conhecimento por parte da mulher ou do homem de que é estéril, via de regra se faz acompanhar de intensa frustração, seguida pelo anseio irreprimível de buscar a intermediação técnica no alcance da reprodução humana".

Segue o autor afirmando que, a realização do desejo de procriar está relacionado com o direito fundamental na utilização das técnicas de procriação artificial que a ciência coloca ao seu dispor se constituindo o direito de procriação em um direito de conteúdo negativo em face do Estado (WIDER, 2007, p. 64).

Todavia, ao mesmo tempo em que a liberdade de procriar se caracteriza um direito fundamental, inegável também, que o conceito de liberdade natural, não pode ser interpretado de forma dissociada do conceito de dignidade natural do ser humano, de modo que, o exercício dessa liberdade deve se operar de forma equilibrada entre esses princípios sendo que, o equilíbrio do direito à procriação reside entre o amparo as liberdades individuais e o direito da pessoa à nascer ( WIDER, 2007p. 66).

Em sua obra "Reprodução Humana Assistida, Aspectos Éticos e Jurídicos" a professora Maria Helena Machado (2008, p. 79-80), faz relevante ponderação com relação às questões polêmicas decorrentes do desenvolvimento de tais técnicas, onde observa que, ao mesmo tempo em que possibilita a um número cada vez maior de pessoas estéreis ou inférteis à realização de um sonho, causam preocupantes controvérsias nas diversas esferas do 
conhecimento, como por exemplo, a definição de embrião, que pode assumir significações diversas, nos diferentes sistemas jurídicos existentes, dando margem a grandes discussões quanto à definição de sua natureza jurídica.

Em relação aos novos direitos decorrentes dos progressos biotecnológicos e seus impactos para a humanidade, Wider $(2007$, p.71-72) pondera que a velocidade com que se disseminaram as técnicas reprodutivas, deu ensejo, em nível mundial, ao surgimento de situações que reclamavam posicionamentos jurídicos para regulamentar as novas realidades estabelecidas.

De igual modo, Minahin (in, Barboza et al, 2003, p. 121) ressalta que em determinadas situações, nas quais se evidencie insuficiência de informações a respeito da complexidade de algumas questões e os efeitos delas resultantes, é melhor que o legislador se abstenha de intervir. Porém, diz a autora, se não se dispõe de uma legislação que interprete e assimile o modo de ser social em relação a estas questões, deve-se, pelo menos, buscar coerência jurídica no tratamento da espécie.

Os temas relacionados à reprodução assistida atraem diferentes olhares sobre os mais diversos aspectos dentre os quais, os religiosos, éticos políticos e jurídicos. Para Grinspan (2008, p. 121-122), as possibilidades científicas de auxilio a concepção é um tema que suscita inúmeras controvérsias em relação a liberdade reprodutiva dos cidadãos pois o desejo de procriar, seja pelo método natural ou artificial implica em riscos associados.

Segundo Meirelles (2008, p. 23), os riscos e os envolvimentos éticos e morais que permeiam as novas tecnologias de reprodução artificial são evidentes principalmente no concernente ao direito à vida $\mathrm{e}$ aos direitos dos seres humanos envolvidos em tais intervenções. Para a autora,

A intervenção na reprodução humana é sim admissível, através da ciência e da tecnologia, desde que respeite o bem maior do ser humano, a vida, além de salvaguardar os meios, valores da reprodução, licitude e a utilização desses conhecimentos em beneficio da humanidade.

Para Schaefer ( in Meirelles, 2008, p. 33), as inovações tecnológicas tem colocado em discussão antigos dilemas e valores tradicionais, considerados absolutos e imutáveis como é o caso do direito a vida. Esse avanços, dada a sua possibilidade de intervenção na vida humana, capazes de conferir novos rumos a humanidade presente e futura demandam especial atenção 
"com a imposição de novos e mais dinâmicos limites éticos, morais e jurídicos" que possam assegurar de forma efetiva a proteção aos direitos e garantias fundamentais dos seres humanos.

\section{DIREITOS FUNDAMENTAIS E A DIGNIDADE DO EMBRIÃO HUMANO}

\subsection{A Dignidade como Atributo de Todo Ser Humano}

Como já mencionado alhures, o direito à procriação se constitui em um direito fundamental, de modo que, ao ser humano é reconhecido o direito fundamental de recorrer às técnicas artificiais de procriação para a realização do desejo de gerar um filho. Porém, conforme esclarece Wider (2007, p. 69), existem ocasiões em que direitos fundamentais que envolvem a intimidade e a vida familiar podem colidir com outros direitos fundamentais igualmente importantes como o direito à vida e a dignidade da pessoa humana.

Para Gisele Echterhoff (2008, p. 75), considerando os novos paradigmas da nossa ciência jurídica a qual revela uma ordem jurídica que confere primazia à pessoa em sua concretude, dotada de dignidade, os avanços biotecnológicos não podem se afastar da premissa de que a dignidade da pessoa humana é o valor axial de nossa sociedade.

Dignidade, na lição de Nunes (2009, p. 48) é um conceito que foi sendo construído no curso da história e que no presente século se apresenta "repleta de si mesma como um valor supremo, construído pela razão jurídica". Garantida por um principio, a dignidade, diz Nunes, não comporta relativismos não podendo "sofrer arranhões e nem ser vítima de argumentos que a coloquem em relativismo" e completa, " a dignidade nasce com a pessoa. É-lhe inata. Inerente à sua essência".

A ideia de dignidade da pessoa humana surge na primeira fase da doutrina cristã com a divulgação da ideia de fraternidade universal, segundo a qual, os seres humanos possuem dignidade porquanto criados à imagem e semelhança de Deus. Já no período inicial da idade média, um novo conceito de pessoa foi construído por Boécio, a qual passou a ser definida como "substancia individual da natureza racional, conceito este que acabou influenciando a noção contemporânea de dignidade da pessoa humana. (SARLET, 1998, p. 33). 
Na opinião de Sarlet (1998, p. 35-37) a base conceitual de dignidade da pessoa humana identificada pela doutrina jurídica mais expressiva da atualidade, se assenta no pensamento Kantiniano segundo o qual "o homem e, de uma maneira geral, todo o ser racional, existe como um fim em si mesmo, não simplesmente como meio para o uso arbitrário desta ou daquela vontade".

Essa concepção Kantiana acerca da dignidade, numa interpretação restritiva remete ao questionamento sobre começo e fim da dignidade além de outras questões que, na esfera da biotecnologia tem assumido grande relevância, como é o caso que diz respeito a proteção jurídica do embrião humano contra os diversos tipos de manipulações (SARLET, 1998, p. 40).

Sob a perspectiva de que o homem é um fim em si mesmo e por esta razão, não pode ser utilizado de forma arbitrária para se alcançar satisfação de determinada vontade, o autor chama atenção para a recíproca sujeição ao qual, de modo geral está vinculado o desempenho das funções sociais, de modo que

[...] a dignidade da pessoa humana, compreendida como vedação da instrumentalização humana, em princípio proíbe a completa e egoística disponibilização do outro, no sentido de que se está a utilizar outra pessoa apenas como meio para alcançar determinada finalidade, de tal sorte que o critério decisivo para a identificação de uma violação da dignidade passa a ser (pelo menos em muitas situações, convém acrescer) o do objetivo da conduta, isto é, da intenção de instrumentalizar (coisificar) o outro SARLET, 1998, p. 57).

Ainda segundo Sarlet (2008, p.75). Com a preocupação de consagrar o princípio da dignidade da pessoa humana previsto expressamente no título dos direitos fundamentais, e categorizá-lo como um dos fundamentos Constitucional, o Estado brasileiro reconhece de forma incisiva que sua existência ocorre em função da pessoa e não o contrário, visto que o ser humano se constitui em finalidade precípua e não em atividade meio estatal.

Acrescenta ainda, o autor, que o constituinte de 1988 optou pela não inclusão da dignidade da pessoa humana no elenco dos direitos e garantias fundamentais, "guindando-a a condição de princípio (e valor) fundamental" (SARLET, 2008, p75). 
A dignidade da pessoa humana, diz o autor, mantém uma relação indissociável com os direitos fundamentais mesmo naqueles ordenamentos jurídicos que não fazem expressa referência, haja vista sua presença no conteúdo dos direitos fundamentais ser inerente.

Nesse sentido, a dignidade da pessoa humana não é apenas uma norma fundamental do ordenamento jurídico, mas também um valor de grande magnitude que, segundo Gisele Echterhoff in Meirelles, 2008, p. 113), deve servir como sustentáculo axiológico na atividade interpretativa em progressos que venham de alguma forma atingir o ser humano e a humanidade como um todo.

\subsection{O Embrião Humano como um ser dotado de dignidade}

O tema relacionado ao reconhecimento da dignidade do embrião humano, segundo Cassiers (in Sarlet; Leite, 2008, p. 193), não é de fácil concepção dadas às proposições cientificas e econômicas que circundam a questão.

Os vários progressos científicos que foram e ainda serão alcançados na área da biomedicina, envolvem embriões humanos, o que remete a inúmeros questionamentos acerca da dignidade desses seres. Para alguns a utilização desses seres para fins de pesquisas científicas, se constitui num retrocesso social no que tange a proteção e respeito pela vida, na medida em que, ao ser destinado para pesquisa o embrião está sendo tratado como "um banal material biológico" (CASSIERS, in SARLET; LEITE, 2008, p. 194).

Na opinião de Machado (2008, p. 67), não se pode assumir nenhuma atitude complacente capaz de admitir a utilização de novas tecnologias que transcendam os limites da preservação dos valores supremos permitidos pela ética e pela moral, pois progresso científico não implica em validade ética nem licitude jurídica.

Ainda, segundo a autora

O desarmamento da ordem jurídica positivada diante das inovadoras possibilidades criadas ciência biomédica, obriga o mundo jurídico a avaliar essas conquistas cientificas, trazendo-as para o campo do direito a fim de verificar até onde a pessoa é beneficiada e até que ponto pode ser prejudicada pelas novas técnicas. Juntamente com importantes descobertas cientificas consideradas como positivas e favoráveis a preservação e bem estar do homem, escondem-se realidades preocupantes [..] que colocam em risco, as próprias características de forma permanente da espécie humana (MACHADO, 2008, p. 69) 
A questão relacionada a tutela jurídica do embrião humano na opinião de Machado (2008, p. 69) tem se convertido em uma questão que suscita maiores conflitos éticos mesmo nos países em que existe legislação especifica sobre fertilização assistida mercê das divergências existentes tanto nas seara jurídica como no campo da bioética com relação a determinação ética do momento da vida humana .

A definição de embrião, varia de país para país. Alguns países adotam uma classificação de forma graduada, classificando o fecundo nos termos: ovo fecundado, préembrião e, por fim, a utilização da expressão feto ocorre depois da formação dos principais órgãos do concebido. Para Machado "Todas as perguntas se resumem em se saber quando começa a existir um sujeito humano, ou seja, a partir de quando um indivíduo pode ser considerado homem" ( MACHADO, 2008.p. 69).

No Brasil, a Lei brasileira de Biossegurança, Lei no 11.105, de 24 de março de 2005, criada com o objetivo de regulamentar o dispositivo constitucional art. 225 da Constituição Federal estabelece normas de segurança e mecanismos de fiscalização de atividades que envolvam organismos geneticamente modificados, além de outras providencias permitindo, em seu artigo $5^{\circ}$ para fins de pesquisa e terapia, a utilização de células tronco embrionárias, obtidas de embriões humanos produzidos por fertilização in vitro e não utilizadas no respectivo procedimento, desde que inviáveis ou congelados há 03 anos ou mais na data da publicação da referida Lei, sendo, em qualquer caso necessário o consentimento dos genitores ${ }^{4}$.

Duramente criticada pelos defensores das causas pela defesa dos direitos humanos contra as ameaças causadas na esfera biotecnológica, o diploma legal, na opinião de Vasconcelos (2006 p. 127), não se revela consentânea com a preocupação em níveis nacionais e internacionais dos organismos empenhados na defesa dos princípios éticos inerentes ao ser

${ }^{4}$ Art. 5o É permitida, para fins de pesquisa e terapia, a utilização de células-tronco embrionárias obtidas de embriões humanos produzidos por fertilização in vitro e não utilizados no respectivo procedimento, atendidas as seguintes condições:

I - sejam embriões inviáveis; ou

II - sejam embriões congelados há 3 (três) anos ou mais, na data da publicação desta Lei, ou que, já congelados na data da publicação desta Lei, depois de completarem 3 (três) anos, contados a partir da data de congelamento.

$\S 1$ 으 Em qualquer caso, é necessário o consentimento dos genitores.

$\S 2$ I Instituições de pesquisa e serviços de saúde que realizem pesquisa ou terapia com células-tronco embrionárias humanas deverão submeter seus projetos à apreciação e aprovação dos respectivos comitês de ética em pesquisa.

§ 3 ó É vedada a comercialização do material biológico a que se refere este artigo e sua prática implica o crime tipificado no art. 15 da Lei ${ }^{\circ}$ 9.434, de 4 de fevereiro de 1997. 
humano representando, "um autêntico contra-senso jurídico no que tange ao tratamento dispensado à vida humana nascente, mais precisamente, aos embriões excedentes na medida em que sacrifica e prescreve prazo de validade para suas vidas ."

A permissão para o que, Vasconcelos (2008, p. 130) chama de "embrionicidio" representa, em sua concepção uma "verdadeira afronta ao Estado Democrático de Direito vez que, ofende os princípios, direitos e garantias fundamentais inerentes à condição humana insculpidos em nossa ordem constitucional.

Correa e Sgreccia (2007, p. 334), asseveram que "o respeito devido ao embrião humano tem inicio com as modalidades e condições nas quais se dá a concepção". A questão, segundo afirmam, envolve um critério de ordem moral que "emergiu na consciência ética em relação ao desenvolvimento contemporâneo de técnicas de fecundação dirigida e que estão levantando problemas de licitude moral".

Nesse contexto, assinalam os autores que o embrião humano não pode ser gerado de forma indiscriminada, mas tão somente de modo a corresponder à dignidade de um sujeito humano sob pena de estar sendo reduzido a um "objeto de desejo", de forma que sua vinda ao mundo não estaria representando um "ato de amor", mas apenas um "produto de laboratório". Todavia, ainda que produzido deste modo, o embrião gerado in vitro, é fruto da concepção de modo que sua dignidade humana não há de ser questionada.

Para os autores, os direitos do embrião merecem ser protegidos, independentemente da forma de fertilização, haja vista a proteção dada pelo ordenamento civil pátrio ao nascituro, desde sua concepção, de modo que todos os direitos conferidos pelo ordenamento jurídico ao nascituro devem ser estendidos ao embrião in vivo e in vitro, considerando que estes seres devem ser vistos como pessoa e não como coisa passível de transferência alienação ou destruição (CORREA E SGRECCIA, p. 335-336).

Nas palavras de Domingo Basso (2005, p. 30), sempre haverá algo evasivo na experimentação pura já que "a biogenética pode descrever o processo embriológico, desde a fecundação até o parto, porém não poderá nunca estabelecer o momento da constituição da pessoa humana." Tal ocorre porque a determinação da unidade física do embrião não é suficiente para resolver o problema da personalidade ontológica.

Apesar dos avanços a passos agigantados da ciência atingindo um alto grau de conhecimento sobre a natureza biológica dos seres humanos, o mistério da reprodução, 
segundo Basso ( 2005, p. 29-30) é sobremodo complexo e perfeito e ainda estamos muito longe do conhecimento completo e a cada dia, a ciência nos surpreende com dados novos. Nesse sentido, o autor afirma que " La biogenética,puede describir el proceso embriológico desde la fecundación hasta el parto, pero no podrá nunca estabelecer el momento de la constitución de la persona humana".

O conceito de humano, considerando unicamente dados biológicos, segundo o autor, não se confunde com o conceito de humano considerando em sua totalidade que supera em muito o conceito exclusivamente biológico. Esta é uma questão que, segundo Basso (2005, p. 30), tem dado ensejo à confusão entre os investigadores do tema, porquanto uns invalidam o campo dos outros, de modo se torna difícil definir quem quer falar como cientista, como filósofo ou como teólogo.

Para Vicente de Paulo Barreto (in Barboza et al. p. 224, a utilização como sinônimos, na linguagem comum das expressões "ser humano" e "pessoa humana" conduziu ao entendimento de pessoa como sendo característica de humano. Daí ser necessário substantivar a ideia de pessoa humana para que se possa definir limitações quanto à licitude ou ilicitude das práticas tecno-científicas que intervenham na vida humana.

As características ontológicas da pessoa humana, na opinião do autor são "a racionalidade e a consciência, o que lhe confere a condição de sujeito de direitos e deveres. A questão que se coloca, todavia, é em relação à definição do que é pessoa humana, cuja resposta, na opinião do autor é fundamentalmente de natureza moral, porque a biologia não é capaz de responder a essas indagações de modo que tais questões se constituem em um desafio para a reflexão contemporânea.

Para o professor de direitos humanos, Reinaldo Pereira e Silva (2003, p. 104-105) o respeito que é devido à dignidade humana como a mais consequente implicação do reencontro do direito com a ética se assenta em dois desdobramentos da ideia de duração, a saber:

[...] 1) todos os integrantes da espécie humana devem ser igualmente respeitados; e 2) o respeito deve ser assegurado independentemente do grau de desenvolvimento individual das potencialidades humanas, isto é, desde a concepção, ainda que extra-uterina, até a fase adulta. Somente afastando-se das limitações mecanicistas da tecnociência é possível afirmar que todo ser humano é pessoa e possui direitos que emanam de sua própria natureza. 
No que diz respeito aos direitos do embrião, sustenta que a garantia constitucional, assegurada por este princípio alcança o homem "independentemente de determinadas qualificações características ou capacidades atuais", de modo que, a única condição necessária para possuir dignidade humana é "ser humano", não importando o estágio de seu desenvolvimento, valendo tanto para homens individualizados como considerados universalmente (Bockenforde, in Sarlet e Leite, p. 63).

Nesse contexto, percebe-se ser a dignidade da pessoa humana não apenas uma norma fundamental do ordenamento jurídico, mas também um valor de grande magnitude que, como observa Gisele Echterhoff, deve servir como sustentáculo axiológico na atividade interpretativa em progressos que venham de alguma forma atingir o ser humano e a humanidade como um todo.

\section{CONSIDERAÇÕES FINAIS}

No presente trabalho foi realizada uma breve abordagem sobre a liberdade de procriação por meios de tecnologias artificiais como um direito fundamental frente à dignidade do embrião humano utilizado nessas tecnologias, considerando a natureza humana e a dignidade destes seres como sujeitos de direitos e, portanto, merecedores de proteção aos seus direitos e garantias fundamentais.

Foram analisados os progressos científicos alcançados no ramo das ciências biotecnológicas, notadamente na utilização das técnicas de reprodução assistida, seus reflexos no campo dos dos direitos humanos, em que se constatou a existência de muitos questionamentos com relação às perspectivas de riscos e danos perpetráveis à integridade dos seres humanos, assim como às inquietações relacionadas a dilemas éticos e jurídicos que o tema suscita.

Da análise procedida foi possível constatar também importantes avanços alcançados na área das ciências biomédicas, notadamente na utilização das técnicas de reprodução assistida, os quais possibilitaram para muitos indivíduos a concretude dos direitos fundamentais reconhecidos constitucionalmente em relação à liberdade de procriar. 
Foi possível verificar que embora seja um direito fundamental, o direito de procriação por meio de técnicas artificiais suscitam vários debates do ponto de vista éticojurídico, considerando o envolvimento de outros direitos fundamentais como é o caso da dignidade do embrião humano, utilizado na manipulação dessas técnicas.

A análise realizada permitiu ainda aferir que o reconhecimento da dignidade da pessoa humana decorre da própria existência do ser humano como tal, sendo-lhe inerente e indissociável dos direitos fundamentais constituindo-se em um verdadeiro pilar axiológico de cunho universal e humanístico que justifica a ordem constitucional em um Estado democrático de direito.

Observados os contextos expostos pode-se inferir que em relação à dignidade do embrião existe no pensamento atual, a ideia de transcendência da dignidade humana reconhecia para alcançar não apenas a pessoa já dotada de personalidade, mas o ser humano em sua totalidade, qualquer que seja o estágio de seu desenvolvimento de modo que, ao embrião humano também é reconhecida sua dignidade como lhe sendo inerente.

Afinal, pode afirmar que os avanços científicos no campo da biotecnologia têm atingindo níveis extraordinários e sem dúvida, trazem reconhecidos benefícios para a humanidade, mas, também, suscitam muitos debates no campo da ética e do direito face às dificuldades da ordem jurídica em acompanhar com sincronia essas realidades que se apresentam.

Do exposto, pode-se concluir que o ritmo veloz com que se produzem as conquistas científicas no meio social, têm representado um verdadeiro desafio para o direito que com o científico, é nitidamente perceptível, segue numa marcha assincrônica gerando justificáveis inquietações haja vista serem questões de que direta ou indiretamente envolvem direitos e liberdades individuais e reclama observância aos valores universais que preservam os princípios consagrados universalmente e construídos historicamente numa sociedade.

\section{REFERÊNCIAS DAS FONTES CITADAS}

AGUILAR, Juan Roberto Sebastian. Estado Historia y Política: Definiciones, pensadores e historia de Las Ideas Políticas. Delta Editora. Parana, Entre Rios. Argentina, 2002. 
BARBOZA, Heloisa Helena. Técnicas de Reprodução Assistida - As Leis ajudam?.In: SOUZA, Maria do Carmo Borges de Moura Marisa Decat; GRYNSZPAN, Danielle. Vivência em Tempo de Reprodução Assistida: o dito e não dito: Rio de Janeiro, Revinter, 2008.

BARBOZA, Heloisa Helena. Princípios do Biodireito. In: BARBOZA Heloisa Helena, BARRETTO, Vicente de Paulo. (orgs.) Novos Temas de Biodireito e Bioética: Rio de Janeiro: Renovar, 2003.

BASSO, Domingo F. Nacer y Morir Con Dignidad: Estudios de Bioética Contemporanéa, 4. ed.-Buenos Aires: Lexis Nexis, Argentina, 2005.

BOBBIO, Norberto. A Era dos Direitos; tradução de Carlos neto Coutinho; apresentação de Celso Lafer- Nova ed. Rio de Janeiro:Elsevier, 2004.

BÍBLIA, Português. A Bíblia Sagrada: Antigo e Novo Testamento. Tradução de João Ferreira de Almeida. Edição rev. e atualizada no Brasil. Brasília: Sociedade Bíblia do Brasil, 1969.

BRASIL, Decreto n.2519/98 Promulga a Convenção sobre Diversidade Biológica, assinada no Rio de Janeiro, em 05 de junho de 1992. disponível em: <https://www.planalto.gov.br>. Acesso em 15 ago.2016.

BRASIL. Lei 11.105/2005 Regulamenta os incisos II, IV e V do $§ 1^{\circ}$ do art. 225 da Constituição Federal, estabelece normas de segurança e mecanismos de fiscalização de atividades que envolvam organismos geneticamente modificados - OGM e seus derivados, cria o Conselho Nacional de Biossegurança - CNBS, reestrutura a Comissão Técnica Nacional de Biossegurança - CTNBio, dispõe sobre a Política Nacional de Biossegurança PNB, revoga a Lei no 8.974 , de 5 de janeiro de 1995, e a Medida Provisória nํㅜ 2.191-9, de 23

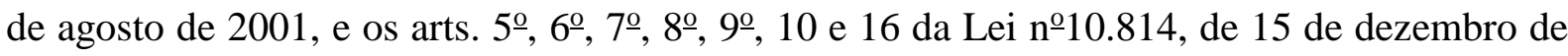
2003, e dá outras providências. Publicada no D.O.U. de 23.03.2005. Disponível em: < https://www.planalto.gov.br>. Acesso em 06. set.2016. 
CASABONA, Carlos Maria Romeo. Biotecnologia Direito e Bioética: Perspectivas em Direito Comparado. Belo Horizonte: Del Rey, 2002.

CORREA, Juan de Dios Vial; SGRECCIA, Elio. Identidade e Estatuto do Embrião Humano. Belém: EDUSC, 2007.

CRUZ, Paulo Márcio; STELZER, Joana (orgs.). Direito e Transnacionalidade. Curitiba: Juruá, 2009 p. 173 a 200.

GORCZEVSKI, Clovis. Direitos Humanos: dos primórdios da humanidade ao Brasil de hoje. Porto alegre: Imprensa livre, 2005.

MACHADO, Maria Helena. Reprodução Humana Assistida: aspectos éticos e jurídicos. Curitiba: Juruá, 2008.

MEIRELLES, Jussara Maria Leal (Coord.). Biodireito em Discussão. Curitiba: Juruá, 2008 .

MYSZCZUK, Ana Paula, Genoma humano: Limites Jurídicos à sua Manipulação. Curitiba: Juruá, 2005.

NUNES, Luiz Antônio Rizatto. O Princípio Constitucional da Dignidade da Pessoa Humana. Doutrina e jurisprudência. São Paulo; Saraiva 2002.

PECES-BARBA, Gregorio. Curso de Derechos Fundamentales: Teoría general. Madrid: Universidad Carlos III, 1995.

PIOVESAN, Flavia. Temas de Direitos Humanos São Paulo, Saraiva, 2010.

RIFKIN, Jeremy. O Século da Biotecnologia: A Valorização dos Genes e a Reconstrução do Mundo. Tradução e Revisão Técnica: Arão Sapiro; São Paulo: Makron Books, 1999.

RODRIGUES, Maria Rafaela Junqueira Bruno. Biodireito: Alimentos Transgênicos. São Paulo: Lemos e Cruz, 2002. 
SANTOS, Maria Celeste Leite Cordeiro dos. Imaculada Concepção. São Paulo: acadêmica, 1993.

SANTOS, Antônio Silva. Os transgênicos e a Vida: para onde vai a biotecnologia. Dsiponível em:http//conjur.uol.com.br.1999. Acesso em: 29/08/2016.

SARLET, Ingo Wolfgang. A Eficácia dos Direitos Fundamentais: uma teoria geral dos direitos fundamentais na perspectiva constitucional. 10 ed. Porto Alegre: Livraria do Advogado, 2010.

SARLET, Ingo Wolfgang. Dignidade da Pessoa Humana e Direitos Fundamentais na Constituição Federal de 1988. 7 ed. Porto Alegre: Livraria do Advogado Editora, 2009.

SARLET, Ingo Wolfgang; LEITE, George Salomão. Direitos fundamentais e Biotecnologia. São Paulo: Método, 2008.

SHERWOOD Robert M. Propriedade Intelectual e Desenvolvimento Econômico; Tradução De Heloisa Arruda Villela. São Paulo, Editora da Universidade de São Paulo, 1992.

SILVA, Reinaldo Pereira e. Biodireito: A Nova Fronteira dos Direitos Humanos. São Paulo: LTR, 2003.

VASCONCELOS, Cristiane Beuren. A Proteção Jurídica do Ser Humano In Vitro na Era da Biotecnologia. São Paulo: Atlas, 2006.

WIDER Roberto, Reprodução Assistida: Aspectos do Biodireito e da Bioética. Rio de Janeiro: Lúmen Juris, 2007. 